\title{
REALIZATION OF THE RIGHT TO HEALTH PROTECTION IN INSURANCE MEDICINE: THE FIRST EXPERIENCE OF COVID-19
}

REALIZACIÓN DEL DERECHO A LA PROTECCIÓN DE LA SALUD EN LA MEDICINA DE SEGUROS: LA PRIMERA EXPERIENCIA DE COVID-19

\author{
Pavlo Lutsyuk* \\ Inna Bolokan ** \\ Iryna Davydova*** \\ Alina Chanysheva ${ }^{* * * *}$ \\ Svitlana Yakymchuk ${ }^{* * * * *}$
}

\begin{abstract}
This article analyze the effectiveness of insurance medicine and the negative consequences of its work, which we could observe in the first period of the pandemic. The research methodology is based on general and special scientific methods, in particular: formal-legal, historical-legal, comparative analysis, and modeling. The procedure and issues to be considered are as follows: in the introduction, we will consider the concept
\end{abstract}

\footnotetext{
* Doctor of Legal Science, Professor of the Department of Civil Law and Procedure of the National Academy of Internal Affairs (Zaporizhzhia, Ukraine). https://orcid.org/00000001-5970-2080. lutsyuk.p@gmail.com

** Doctor of Legal Science, Associate Professor of Civil Law Department of Zaporizhzhia National University (Zaporizhzhia, Ukraine). https://orcid.org/0000-0003-1868-7552. innabolokani@gmail.com

*** Doctor of Legal Science, Professor of Civil Law Department National University "Odesa Law Academy" (Odesa, Ukraine). http://orcid.org/0000-0001-5622-671X. divo-ira@ukr.net ***** Doctor of Legal Science, Professor of Civil Law Department National University "Odesa Law Academy" (Odesa, Ukraine). https://orcid.org/0000-0001-5837-6754. chanysheva@onua.edu.ua

***** Ph.D., Associate Professor, Department of Civil law and Process Leonid Yuzkov Khmelnytskyi University of Management and Law (Khmelnytskyi, Ukraine). https://orcid.org/0000-0003-1848-494X. lena.yakimchuk@icloud.com
} 
of "the right to health care" and why it is important; in the first section, we will look at the general state of affairs, figures for different countries, and the first results of the fight against the pandemic; in the second section, we will touch on some of the problems of access to health care in the insurance system and its aggravation in connection with the pandemic; in the third, we will consider the impact of the pandemic on the health insurance system and how it could have been avoided some problems. The results of this study emphasize that the medical insurance system has extremely unsatisfactorily coped with the pandemic and its consequences, and therefore it is necessary at least to carry out a full-fledged official, and at best to develop an urgent comprehensive modernization program, taking into account the above positive experience of other developed countries.

Keywords: Right to Health, Coronavirus, Health Care System, Public Medicine, Private Medicine

Resumen: Este artículo analiza la efectividad de la medicina aseguradora y las consecuencias negativas de su trabajo, que pudimos observar en el primer período de la pandemia. La metodología de investigación se basa en métodos científicos generales y especiales, en particular: formal-legal, histórico-legal, análisis comparativo y modelización. El procedimiento y los temas a considerar son los siguientes: en la introducción se considerará el concepto de "derecho a la atención de la salud" y la razón de su importancia; en la primera sección, veremos el estado general de la situación, las cifras de diferentes países y los primeros resultados de la lucha contra la pandemia; en la segunda sección, abordaremos algunos de los problemas de acceso a la atención médica en el sistema de seguros y su agravamiento en relación con la pandemia; en el tercero, consideraremos el impacto de la pandemia en el sistema de seguro de salud y cómo podrían haberse evitado problemas. Los resultados de este estudio destacan cómo el sistema de seguro médico ha enfrentado de manera extremadamente insatisfactoria la pandemia y sus consecuencias, y por lo tanto es necesario al menos llevar a cabo un funcionario de pleno derecho, y en el mejor de los casos desarrollar un programa de modernización integral urgente, teniendo en cuenta la experiencia positiva anterior de otros países desarrollados.

Palabras clave: Derecho a la salud, Coronavirus, sistema de salud, medicina pública, medicina privada

Summary. I. Introduction. II. Analysis of recent research. III. Results and discussion. III.1. General look at strategies and early results in the fight against 
Realization of the Right to Health Protection in Insurance Medicine: the first experience...

the pandemic. III.2. Japan and South Korea cases. III.3. Germany, the UK and the US cases. III.4. Consequences of lack of insurance and high prices for medical services. III.5. The impact of the pandemic on the health system. IV. Conclusions. References.

\section{INTRODUCTION}

Access to healthcare is a fundamental and essential principle of any modern state. State stability, working capacity of the population, and, accordingly, economic growth, demographic and social prospects directly depend on the health of the population.

The right to health or as defined by the International Covenant on Economic, Social and Cultural Rights (1966) "the right to the highest attainable standard of physical and mental health" is enshrined in Article 12 of the Covenant, which has been signed and ratified by most countries.

Therefore, each state builds its own health care system and seeks to eradicate or at least restrict drug addiction, alcoholism, and tobacco smoking with the ensuing consequences for health. There are many national and international programs to combat various global diseases: HIV, tuberculosis, hereditary diseases, cancer, and more recently the Covid-19 epidemic.

With the development of the pandemic, public health protection came to the fore for governments around the world. The epidemic not only became a threat to national security and demography but also undermined global economic ties, became one of the causes of protests and unrest around the world, disrupted the trend towards globalization, increasing the importance of access to healthcare and its quality.

In this regard, questions arise: to what extent were the national health systems prepared for the pandemic, did the pandemic affect the quality of other health services, and also how effective different types of health care were and how they provided the population with access to health services and, in particular, to treatment and prevention of Covid-19 itself. Moreover, despite the fact that it may be too early to draw any definitive conclusions because the pandemic is still far from over, interim conclusions are simply necessary to understand what officials, civil society organizations, and ordinary citizens can and must do to more effectively fight against Covid19 , to maximize the realization of everyone's right to health.

Considering that the overwhelming majority of developed countries of the world use public free medicine or mixed systems, the main analysis of insurance medicine will be done through the prism of the United States, as 
well as how private medicine has shown itself in European and Asian countries with different approaches and regulations.

\section{ANALYSIS OF RECENT RESEARCH}

The issue of the right to health care and how effectively the insurance system implements it is well covered from different positions, however, the Covid-19 pandemic has become not only a test for different medical systems, but also for the positions of various scientists and organizations that justify them.

Thus, Saad (2019) highlighted the trends of deterioration in the availability of healthcare, postponement of treatment, diagnostics, and operations. Gallup (2019). More Americans Delaying Medical Treatment Due to Cost. The author concludes that this is a stable trend over the past 20 years, associated, on the one hand, with the growing gap between rich and poor and the "extinction of the middle class," and, on the other hand, with errors in regulation and lobbying of major players in insurance medicine.

The recent reform of the ACA, unfortunately, did not reach any significant effectors, a group of scholars' notes in their study Collins, Bhupal and Doty (2019) "Health Insurance Coverage Eight Years after the ACA".

Insurance provided by employers was particularly affected as no adequate system of tax compensation or other incentives was developed, especially for small businesses. Similar processes are already being considered in Britain by Denis Campbell (2019). NHS operations cancelled as consultants work to rule in pension's standoff.

There, due to the confluence of insane bureaucracy and a progressive tax system for highly qualified specialists, there is a shortage of highly qualified doctors, because some have to deal with their retirement savings, while others have no reason to work overtime. Denis Campbell concludes that the current system is not viable and urgently needs more serious investigation, otherwise the UK health care system will be in a vulnerable position. Unfortunately, his predictions came true.

Also noteworthy are works devoted to the formation, development, and health problems in Japan (Matsuda, 2005) and Korea (Lee, Kim, Seo \& Lee (2017), Cho, Chung, Joo, Park, Joh \& Kim (2020)). Their original approach and experience of the functioning of a mixed system of public funding and private hospitals are very interesting and, based on the results of the fight against the pandemic, is useful to all countries.

There are many interesting works, in particular Dorn (2020), Giordano (2019), Skinner and Mayer (2007), Cohen, Terlizzi, Martínez, and Cha (2020), Ayanian, Weissman, Schneider, Ginsburg and Zaslavsky (2009), 
Brown, Ojeda, Wyn and Levan (2000), which in one way or another relate to the right to health care, its availability, and the problems of insurance medicine for different periods. However, there is no consensus in the scientific community regarding the reasons for the deterioration in the quality of insurance medicine, opinions are directly opposite: bureaucracy, excessive regulation, and government intervention, or vice versa, the arbitrariness of private medical companies and inaction, or lack of leverage from state regulatory bodies. But more importantly, there is often no understanding of the scope of what is happening, because everyone works in their own small area. Let's try to consider the situation as a whole, and in particular how the Covid-19 pandemic affected the availability of insurance medicine.

\section{RESULTS AND DISCUSSION}

\section{III.1. General look at strategies and early results in the fight against the pandemic}

During a pandemic, there are various ways of estimating coronavirus death statistics, including making various assumptions about how well government containment measures are working. However, ethical and practical limitations in the study of human disease or epidemiology, in general, make it impossible to conduct experiments that can definitively establish the effects of restrictive government measures and medical interventions. Consideration through the prism of the total number of infected people does not seem to us to be any significant information in terms of the effectiveness of the medicine, because in this case we are talking about a huge number of factors and, first of all, government quarantine measures, people's behavior and attitudes, climatic and environmental factors. Therefore, to judge the medical system, we believe that it is necessary to speak precisely about the mortality rates to the total number of cases.

The most common way to measure Covid-19 deaths is by dividing the total number of people who have died from the disease by the number of people with diagnosed infection from the population of the country or state, in which they live, to assess the impact of government action.

However, this type of statistics does not take into account that many other factors can affect mortality rates, such as genetics, culture, hospital protocols, population density, age, financial situation, sports, proper diet, congenital diseases, and so on, which makes an objective an estimate based solely on general mortality statistics is almost impossible. 
For example, New York State has imposed some of the most stringent restrictive measures in the United States, but as throughout the pandemic, by November 2020, the state's coronavirus death rate was double that of nearby Florida, where restrictive measures were fairly moderate. New York showed 33.1 thousand deaths, while Florida only 16.8 thousand, although the total number of infected in Florida was more than in New York, 812 thousand versus 514 (Worldometers, 2020). Thus, New York, despite all the restrictions, received a mortality rate in the region of $6.5 \%$, while Florida, which introduced lighter restrictions, only $2 \%$.

Therefore, the only places in which the comparison of "dry" statistics is applicable are states, countries, and separate areas that are similar or the same in cultural, economic, and genetic aspects, for example, the Scandinavian countries, in which the main differences are reduced to government intervention or local authorities.

However, what remains is the fact that the United States, despite its best efforts, ended up in the top ten countries with the worst Covid-19 deaths per million, next to countries like Mexico, Bolivia, and Brazil, which brings us to the question of what was the main problem of the United States in the fight against the pandemic and what strategies were followed by other countries that successfully coped with the crisis.

So far, we can say with confidence that the main criterion for low mortality from coronavirus is a well-functioning "mass" medicine that consistently provides access to healthcare for the largest number of citizens under centralized management. Among the undisputed leaders were Singapore with a mortality rate of $0.05 \%$, Israel with $0.8 \%$, the United Arab Emirates with $0.36 \%$, Luxembourg with $0.8 \%$, Iceland with $0.3 \%$, Slovakia with $0.48 \%$, with mortality to detected infected ratio-among those whose statistics are reliable. Perhaps this is some kind of distortion in small countries, however, it is also possible that small countries were able to cope more effectively with the pandemic. The best results in large countries are in South Korea $1.75 \%$ and Japan $1.72 \%$, although we have to admit that there are problems with testing and the accuracy of the figures given (Worldometers, 2020).

However, all these countries have one thing in common-they all conducted a huge number of tests per capita at the early stage of the spread of coronavirus infection, up to 1.7 tests per person in Luxembourg, while not burdening citizens with unnecessary costs and providing them with access to quality healthcare if the infection was found.

In the case of Singapore, of course, authoritarian control measures have also performed well, including compliance with restrictive measures through cameras and heavy fines for violating them, thanks to which the 
population has been disciplined and rigorously following state regulations for a long time.

\section{III.2. Japan and South Korea cases}

There are two cases that deserve an especial consideration, Japan and South Korea. In both the discipline and familiarity of the mask regime for the population played a factor, since this is a regular practice in these countries. Let's take a quick look at how their systems work.

In the Japanese health care system, medical services, including disease-specific screening, are provided at no direct cost to the patient, including antenatal care and infectious disease control, provided by state and local governments. Payment for personal health care services is offered through the universal health insurance system, which ensures relative equality of access and fees set by a government committee (Nomura \& Nakayama, 2005).

Japan has two main health insurance systems that cover the vast majority of the population. The first, the national health insurance system, covers mainly smallholders and their families, people with disabilities, and other unemployed persons. The second is that the employee insurance system covers all employees and their dependents and is the largest in Japan. The insurance does not provide any restrictions on the choice of a doctor and a hospital. For the majority of medical services, a share of patients is provided in the range from 10 to $30 \%$. At the same time, the upper limit of payments is set at 677 dollars per month for an average family. The average Japanese family pays for medical services for 2,300 dollars a year from personal funds. For some segments of the population, such as peasants, fishermen, and government officials, there are special health care programs that are rather limited in scope. The unemployed remain participants in insurance schemes at their former place of work, although they are not required to pay contributions. Since 1973, government-funded insurance has extended to all seniors.

The country has a system of supplementary private insurance, which is not in great demand. It accounts for no more than $1 \%$ of total health spending in the country. However, the vast majority of hospitals and clinics in Japan are in private hands, however, since all tariffs for payment for their services are set by the authorities, for patients there is no difference between private and public medicine.

At the same time, Japan spends about $8.1 \%$ of its GDP on the health care system, in contrast to the States, where this figure is already twice as large. The problem of endless cost increases in many countries is being 
tackled without resorting to the rationing characteristic of public health insurance systems in many other countries, but through competent public administration of the health care system with ten-year plans and a significant share of consumers in paying for health services (Matsuda, 2019).

The medical system of healthcare in South Korea is more marketoriented, there are no government 10-year plans, but the standards it sets, financial flows, and generally transparent rules of the game have become the key to success.

The government of the Republic of Korea 30 years ago managed to do what the owners and managers of many private clinics can only dream of so far - to build a system for the provision of medical services with direct government funding and equal access for providers of all forms of ownership. Over the past decades, the concept has proven its worth: now South Korea is one of the five countries with the most efficiently organized healthcare.

International experts call the Korean system of medical services "balanced", regularly including the republic in thematic ratings. For example, in the ranking of countries with the most efficient healthcare systems published by Bloomberg in 2018, South Korea was ranked fifth, leaving behind Israel, Japan, Switzerland, and behind Hong Kong, Singapore, Spain, and Italy. Korea tops the current ranking of countries with the best quality of care, compiled by the largest Asian health resource MIMS Today (Goncharona, 2019).

The main holder and manager of the state budget for the industry is the National Health Insurance Service, which interacts with clinics directly, without the participation of insurance companies. At the same time, public and private clinics have equal access to the system of state guarantees and compete with each other.

There is a universal system of compulsory health insurance, in which the state pays up to $50 \%$ of the cost of outpatient care, and up to $80 \%$ of services provided in the hospital, the rest of the costs are covered by copayments of patients (Lee, Kim, Seo \& Lee, 2017).

It is noteworthy that Korea, which tried in every possible way to copy the economic and technological experience of the United States, ignored the American model of health care, focused on private insurance. But the Koreans largely adopted the Japanese concept, which implies strict government administration of the medical services industry, although they adapted it to their realities. At that time, letting private clinics into the system is the only way to ensure wide access of the population to medical care.

As a result of the reform, independent providers received the same opportunities to connect to the system of state guarantees as to their state 
competitors. The choice of the clinic was left to the patient, and the national insurance fund compensated the costs of the medical facility, regardless of the form of ownership.

This historical context has shaped contemporary Korean medicine. Now the national health insurance system covers $97 \%$ of the country's population, the remaining $3 \%$ of citizens with low income is covered by the state program The Medical Aid Program. State orders for medical services are mainly served by private providers, whose share of the total number of medical institutions operating in the country exceeds $94 \%$.

The health care system is focused on maximum savings and the most efficient use of state insurance funds. In particular, the country has a largescale medical examination program, which is regularly notified to the entire population. If the patient neglected the preventive examination, and subsequently was diagnosed with a disease requiring surgical intervention, then he will pay for such an operation out of his pocket or seek support from charitable foundations. The state washes its hands.

There is no state ambulance system in the republic either; in case of emergency, "paramedics" from the rescue service go to the sick or injured and, if necessary, transport patients to medical facilities. There is no system of calling a doctor at home in Korea either-such a service, taking into account the average salary of a Korean doctor of at least 60 dollars thousand a year, would be prohibitively expensive here.

Since the general medical examination has developed among the population the habit of undergoing preventive examinations and a commitment to a healthy lifestyle, private operators are boldly investing in expanding the line of checks. Now in Korea, in-depth examinations are very popular, including a wide range of laboratory tests and radiation diagnostics, which can be completed in just 3-4 hours, paying 500-1,700 dollars.

Of course, there are also problems, and the main one is the increase in the cost of expenses. Healthcare spending per capita in South Korea increased by $292 \%$ between 2004 and 2018, analysts estimate, compared with just $83 \%$ in Taiwan.

One of the reasons is a shift in emphasis and even a bias towards expensive specialized care. With the freedom to choose, patients tend to seek help from large and third-tier hospitals (the highest ranking), which, of course, increases the costs of the national health insurance fund and the number of copayments (Cho, Chung, Joo, Park, Joh \& Kim, 2020). The factor of "medical tourism", both domestic and international, also influences, when the best hospitals are trying to get from all over South Korea or even Asia. Of course, in such a situation, the majority of the 
population of the region where such a hospital is located becomes unable to pay for its services and is forced to go to others (Sung \& Park, 2019).

Thus, the Asian tigers have built different but effective systems of "mixed" health care, where the state directly from the budget or through payments to employers finances the medical system where transparent rules and competition between medical institutions reign, encouraging them to provide the best quality of care at the lowest cost. At the same time, the state keeps its finger on the pulse, and when the pandemic just began, it quickly managed to organize a private medical sector. Once they learned from the United States, now the United States and other countries should learn from them.

Once again, the pandemic showed that a broad, well-funded public health sector, which provides most of the entire population with access to health care without splitting into categories by financial status, or a high state influence on the private sector with its good coordination and coverage of its costs through budgetary money, could have played a key role in the fight against the pandemic in obtaining the best results in testing the population and one of the lowest death rates from the coronavirus.

\section{III.3. Germany, the UK and the US cases}

However, government regulation can be detrimental if not consistently implemented. A striking example of this is the once-famous health care system in Germany.

The system of health insurance for citizens originated in Germany in 1881 during the reign of Kaiser Wilhelm I and Reich Chancellor Otto von Bismarck. The calculation was simple: healthy and employed citizens paid contributions to the health insurance fund, which financed the treatment and maintenance of sick fellow citizens. Solidarity was the main tenet of Bismarck's social security. The employee paid two-thirds of the premium to the health insurance fund, and the employer paid one third. Times have changed today: the employee and the employer pay half of the sum insured.

Since 2000 , healthcare spending has grown steadily by $1-2 \%$. Over the past 20 years, the German healthcare system has undergone 14 reforms. Most of them did not bring tangible results. The prices of medicines have increased, co-payments have been introduced for dental services, and a mandatory quarterly patient contribution for medical care for 10 euros. The German health care system still offers full health care to citizens, but it has already begun to slip.

For many years, there has been a debate about the size of doctors' fees. It got to the point that more and more medical practitioners can finance 
the maintenance of their practices only thanks to patients with private insurance.

About ten percent of patients have private insurance, but only people with high wages can afford it: entrepreneurs and officials. Their monthly contributions do not go to the compulsory insurance funds, which work precisely on the principle of social solidarity and where unemployed, elderly, and seriously ill people are insured. Only recently has the government obliged private insurance companies to offer health insurance to socially vulnerable patients. However, it is still very difficult for people with low incomes to get private health insurance.

All previous reforms aimed to reduce health care costs. And the created state fund should contribute to the development of healthy competition between insurance companies. But, according to Jochen Pimpertz, an employee of the German Institute for Economic Research in Cologne, the foundation is not able to change the situation radically. One of the reasons is that patients do not understand the cost of medical care. A part of the medical insurance tax is automatically deducted from their salaries, and people no longer need to be interested in what exactly the funds they deduct are spent on, as Pimpertz (2017) said.

Only patients with private health insurance know how much their medical care costs: for each visit to the doctor, they receive a bill, which they send to their health insurance company for repayment. The overwhelming majority of patients who pay contributions to the compulsory insurance funds do not know how their health insurance company pays with doctors.

Thus, even though Germany is still strange with one of the best medical services, at the first serious problems of the state with the budget, the entire national health system will be in jeopardy. Already, there are many unsolvable problems - from taking into account the interest of doctors and their remuneration to the steady rise in prices and the destabilization of the state solidarity system.

Something similar has already been confronted by the more marketable health care system in the United Kingdom. However, this country has launched austerity policy in 2010 and reduced funding for the National Health Service (NHS), thereby undermining the effectiveness of health care. Due to the decisions of the British government, the cuts in funding even before the final aggravation of the situation, as the study showed, led to 45,369 deaths in the period 2010-2014, and by 2020 it was predicted three times more (Watkins, et al., 2017). However, after 2015, the situation worsened, so the figures quoted should presumably be higher. This 
shows that the important aspect is precisely good funding and the absence of government obstacles in the work of national health services.

Already by 2019 , more than 4.4 million people were awaiting nonurgent surgery in the UK (Giordano, 2019), and due to interventions in the retirement savings of doctors, their working hours were reduced even more, which led to complications in access to medical services, and tens of thousands of already scheduled operations were canceled (Campbell, 2019).

Therefore, the most important aspects in the issue of health care are not the belonging of hospitals to the public or private sector, but the correct regulatory policy focused on coordinating total health care and providing access to health services for the entire population, including subsidizing health facilities if they begin to suffer losses.

However, regardless of the sector, the state should have a dominant influence over the health care system, preventing sectors from abusing their position and obliging them to provide health insurance or other types of health care, regardless of the financial situation of the populationSwitzerland is one such example of regulation of the private sector, which obliges people to provide insurance, ignoring their medical history.

On the other hand, countries with predominantly private healthcare, low government influence and, accordingly, poor regulation of medicine, such as the United States, on the contrary, face several serious problems, which is why they show some of the worst results in the spread of coronavirus and mortality from her.

This is primarily since in this type of health care the need for private health insurance prevails, the absence of which leads to disproportionately high costs among the population, which makes it extremely costly to undergo medical examinations.

Therefore, for the majority of people, the life-saving insurance is paid by the employer, which, according to the Kaiser Family Foundation, accounts for about half of the entire US population (Kaiser Family Foundation, 2019). However, the pandemic and its restrictive measures led to an explosive increase in American unemployment - it quickly exceeded 20 million jobs, which, accordingly, led to massive losses of employersponsored insurance (U.S. Department of Labor, 2020). And the results of a recent study by the Commonwealth Foundation showed that $40 \%$ of those surveyed, their spouses or partners who lost their jobs during the pandemic, had this type of insurance (Collins, et al., 2020).

Many of them, of course, will still have employer coverage or become eligible for Medicaid or join private insurance schemes for a while, but a significant number are likely to drop out entirely due to financial difficulties (Banthin, Simpson, Buettgens, Blumberg \& Wang, 2020; Dorn, 2020). This 
applies not only to those who have lost their jobs but also to workers who will keep their jobs - they may also face a reduction in insurance coverage, as the crisis has severely affected the financial situation of employers, due to which they began to cut costs.

According to rough estimates, all this could lead to an increase in the number of the uninsured population up to 31-40 million people (Cohen, Terlizzi, Martínez \& Cha, 2020; Collins, Bhupal \& Doty, 2019), the main reason for which is precisely the fact that the US health care system still continues to rely on insurance from employers, while many states continue to refuse to expand the government's Medicaid program without providing the public with any possible alternative at all.

Thus, if in states with a budgetary centralized health care system or at least a serious influence of state regulation, the population, even in the event of unemployment and poor financial situation, still has a chance to receive any minimal medical assistance, then in the case of the private insurance system, many people find themselves on the sidelines not only without money but also without medical care, which ultimately harms the whole society.

\section{III.4. Consequences of lack of insurance and high prices for medical services}

The problem of lack of insurance has always had a great impact on Americans, which became especially noticeable against the backdrop of the pandemic that hit this problem with renewed vigor, despite the efforts of governments around the world focused on helping the population to suppress coronavirus infection.

To see the whole picture, you don't even need to go far. Even the beginning of a pandemic in the United States was immediately marked by the fact that hospitals could legally refuse to save their lives to dying patients due to lack of proper medical insurance, leaving them to die on the street.

A similar case, for example, occurred with a minor who went to the hospital for emergency medical care but was expelled from the medical institution due to lack of insurance, subsequently, which ultimately died on the way to another hospital without receiving medical help (CBS Los Angeles, 2020).

The situation with the refusal to treat patients is not new and extends far from one coronavirus pandemic, but also to urgent surgical operations, such as organ transplantation, disease prevention, and other medical services.

All this is part of a single problem in which paid medical services are too expensive for people, especially for those who do not have health 
insurance that covers part of the cost of these services. This has a negative impact on the health of the population, being a serious deterrent for them from undergoing examinations, receiving proper treatment, using preventive and primary medical services, which is associated with poor health consequences (Majerol, Newkirk \& Garfield, 2015; Institute of Medicine, 2009; Ayanian, Weissman, Schneider, Ginsburg and Zaslavsky, 2009; American College of Physicians-American Society of Internal Medicine, 1999; Brown, Ojeda, Wyn and Levan, 2000; Zuvekas \& Taliaferro, 2003).

The data show that this affects all categories of citizens of all ages: the lack of insurance among adults, for example, leads to significantly less access to medical care if they are sick or injured, as well as to receiving services for the prevention of chronic diseases such as cancer, diabetes, cardiovascular diseases, and others, which also entails a higher chance of being hospitalized for these chronic diseases (Majerol, Newkirk \& Garfield, 2015; Institute of Medicine, 2009; Ayanian, Weissman, Schneider, Ginsburg and Zaslavsky, 2009; American College of Physicians-American Society of Internal Medicine, 1999; Brown, Ojeda, Wyn and Levan, 2000; Starfield, Shi \& Macinko, 2005).

As well as adults, children who do not have health insurance are also significantly less likely to receive appropriate treatment for diseases such as asthma, or, more critically in terms of disease prevention, dental care, undergoing routine health examinations of the child at all stages of its development, and even vaccination is a routine primary health care service (Institute of Medicine, 2009; Becton, Cheng \& Nieman, 2008). Among other things, insurance is also of great importance in the context of access to health services for children with special needs or with chronic diseases (Institute of Medicine, 2009; Skinner \& Mayer, 2007).

However, it should be understood that the availability of insurance does not necessarily solve this problem, since insurance often includes only basic services, such as visits to doctors or general procedures and tests, while examinations, operations, and full treatment, especially when it comes to specific diseases may not be included in the available insurance coverage at all, therefore, it would be wrong to absolutize the number of insured persons without ranking according to their insurance coverage.

In addition, while adequate insurance coverage can also show a large cost differential versus no coverage, even in the context of coronavirus treatment, the final cost of treatment can still be prohibitively high, in the tens of thousands of dollars, despite having an insurance plan.

For example, estimates by the independent non-profit organization FAIR Health show that long-term treatment for coronavirus for the uninsured population can lead to bills of up to 75,000 dollars, while for the 
insured, depending on insurance coverage, up to 22,000-35,000 dollars (FAIR Health, Inc., 2020). Depending on the situation, of course, these figures may turn out to be higher.

Nevertheless, it cannot be denied that the availability of health insurance still leads to some positive effects, smoothing out negative consequences - improved access to medical services, prevention, and health examination and, in general, leads to an increase in the use of medical services and improving health indicators of the population (Baicker, 2013; McWilliams, Zaslavsky \& Meara, 2013; Buchmueller, 2005; Freeman, 2018).

For example, one study found that people who were uninsured at age 60-64 but enrolled in the public Medicare health insurance program at age 65 increased their use of clinical health care services (McWilliams, Zaslavsky \& Meara, 2013). Medicaid for previously uninsured persons-its availability has led to an increase in the detection of diseases such as diabetes and the advancement of the necessary medications for appropriate treatment (Baicker, 2013).

Therefore, expanding public insurance and reducing the cost of medical services is an important step towards the health and well-being of the population, which, however, is happening in the States too slowly or not at all, while the main problems in gaining access to quality health care, despite the global economic leadership, lagging behind most developed countries of the first world.

Thus, according to the global analysis of the Global Burden of Disease Study, the United States has the worst indicators of access to health care among countries with a similar income level (Fullman, 2018), while at the same time having the most disproportionately high medical expenses among the whole world, both in relative terms and in absolute per capita expenditures (Sawyer \& Cox, 2018).

This can be seen even from general statistics compiled by the American analytical center Gallup, which found that back in 2019, with just over $10 \%$ of the uninsured population (Tolbert, Orgera \& Damico, 2019), as many as $33 \%$ of Americans postponed treatment of diseases due to the high cost of medical services, while $25 \%$ of $33 \%$ had a serious illness (Saad, 2019).

These numbers are more likely to rise even higher as employer-paid insurance is removed due to job loss or financial hardship when it comes to private insurance plans. First of all, this is due to the specifics of the work of the most widespread and well-established private health care in the United States, insurance, and their poor regulation outside of Medicare and Medicaid insurance programs.

For example, even during a pandemic, according to an analysis by the Peterson Health Center and the Kaiser Family Foundation, the cost of 
diagnostic tests for Covid-19 varied irregularly, depending on the provider, from 20 to 850 dollars per test, which did not include the cost of the visit, the fee for performing the test itself, collecting samples, or any other service that may have been included during testing without the knowledge of the patient (Kurani, Pollitz, Cotliar, Shanosky \& Cox, 2020). Despite new laws requiring insurers to cover the full cost, providers can get around them by charging money for a doctor's visit, in person or through telemedicine, collecting samples at different prices depending on the place of collection, and other services for which the institution will see fit to take the money.

In other words, the final cost of a test due to poor federal health regulation can only be found out at the end of the testing itself, which is used by unscrupulous health care providers, imposing various services on patients or simply including them in the cost, one of which may be imposed preliminary testing for other diseases before a patient is tested for coronavirus, leading to additional bills amounting to hundreds of dollars.

Of course, in the context of testing for Covid-19, this is not limited to this, since, among other things, some groups of patients may not initially be eligible to cover the cost of even the testing itself, despite the adopted law.

These categories of citizens include people who have health insurance plans that do not meet the requirements of the Affordable Care Act, such as short-term policies, or patients who are being tested in an outof-network facility, or, of course, simply do not have insurance - they are again becoming the most vulnerable group of the population, which legislators forget about.

Besides, federal laws do not apply to tests conducted as part of the "return to work" employment program, which requires patients and this category to pay the full cost of testing for testing, despite the critical time when testing for Covid-19 must be affordable and widespread. Information from the media or statements by some companies about free tests and vaccines looks especially outrageous because, in fact, an ordinary American only hears about these excellent initiatives, but he/she has to shell out hundreds of dollars because tests for the virus are "not provided" by the insurance plan (Kliff, 2020).

Thus, the lack of widespread government insurance coverage and poor or absent regulation of health care leads to a myriad of problems and potential victims, mainly due to the high cost of treatment and testing that is not found in other countries. 


\section{III.5. The impact of the pandemic on the health system}

However, the consequences of the pandemic have led to the fact that not only patients but also medical institutions themselves are faced with a large number of problems. Due to the pandemic, hospitals, primary health care facilities, and other health care facilities across the country have started to suffer huge financial losses that threaten their immediate viability. And the main reason for this is the unexpected change in the demand for medical services.

On the one hand, there is no doubt that the Covid-19 pandemic has increased the demand for specialized emergency care, which overwhelmed hospitals and led to huge costs for many patients, which, viewed from the outside, of course, should have increased hospital income due to the huge influx of patients.

On the other hand, however, a sharp drop in demand for conventional services or their replacement with coronavirus treatment has led to a strong reduction in the basic income of health care providers.

Most hospitals have had to postpone or cancel non-urgent surgeries and routine procedures, from inpatient surgery, outpatient surgery, orthopedic procedures to colonoscopy required for colon cancer screening (US Department of Health and Human Services Office of Inspector General, 2020).

All these services accounted for the bulk of the income of medical institutions, however, they were either delayed or canceled to make way for patients with Covid-19, while many hospitals, especially financially unstable ones, had to lay off some of their medical workers or cut their salaries in order to save money, since the urgent re-profiling of hospitals made their services less in demand and more expensive for hospitals (Harris, Sondel \& Schneider, 2020).

Nevertheless, the decline in health care revenues is not all about this.

Among other things, according to the Office of the Inspector General (OIG), hospitals also had to invest heavily in hiring new staff and opening new wards to screen and treat patients infected with coronavirus infection, as well as in acquiring personal protective equipment in unprecedented quantities.

Cumulatively, maintaining wards in isolation, supplying them with drugs, personnel, and equipment, including purchasing ventilators, forced overtime pay for medical staff as hospitals faced an acute shortage of trained nurses, and in some cases covering the costs of nursing childcare and payment transport, led to a huge spike in unplanned costs and layoffs of 
other non-coronavirus patients, medical personnel from hospitals (US Department of Health and Human Services Office of Inspector General, 2020).

Coming to the bottom line, in the first months of the crisis alone, the number of personal visits to doctors fell by $60 \%$, the total financial losses among hospitals, according to the estimates of the American Hospital Association (AHA), by the end of 2020 will amount to about 323.1 billion dollars, and the total employment in the healthcare system more than a million jobs will be cut (Mehrotra, 2020; American Hospital Association, 2020).

This will further exacerbate the health crisis, as the resulting shortage of doctors means that patients may face longer waiting times and delays in care, and in more rural areas people may even lose a single primary care provider (Bodenheimer \& Pham, 2010), while limited access to health care could increase the risk of poor health outcomes (National Association of Community Health Centers and the Robert Graham Center, 2007; Douthit, 2015). Thus, the epidemic not only showed the weak adaptability of private insurance medicine to the need for a general fight against a mass disease, but itself became a victim of a pandemic, like any other business, because it was not ready for a change in the market environment, a decline in the population's ability to pay, postponing unnecessary procedures and the mobilization of doctors, because of which the industry also suffered losses.

\section{CONCLUSIONS}

1. The new crisis showed us once again the imperfection of the health care system based on voluntary insurance, in which many citizens are unable to access health services and treatment due to their high cost. Expanding access to health services is critical to improving public health and reducing health inequalities, and the current state of health insurance systems remains grossly unsatisfactory (as the data show).

2. However, taking the example of Germany, we see that the state solidarity system is not a guarantee of success, although it showed a greater margin of safety. In the USA, there are poor and inconsistent regulatory policy in the health sector from the authorities has also led to the fact that the adopted anti-crisis laws aimed at combating the pandemic and providing citizens with cheaper or free access to health care, such as free testing for coronavirus, proved to be ineffective for many populations, while the target groups (to whom the law was directed) face abuse and imposition of other paid services by medical providers, which negates most of the positive effect of these measures. We recommend setting up a special multi-faceted public state commission, headed by a prosecutor, to conduct an official 
investigation as to why the state authorities are failing in their duties and whether there are signs of lobbying from large pharmaceutical companies. Why it happened is difficult to answer unequivocally and it is beyond the scope of this article. However, we consider it a good decision to create a special versatile public state commission headed by a prominent prosecutor, a lawyer and a physician to conduct an official investigation as to why the state authorities are not doing their job, and why the world's first economy was less prepared than most rich countries. And most importantly, what can be done from the experience of other countries here and now, regardless of political differences. This will help reduce social tensions around this issue and move the discussion in a constructive direction.

3. Considering that a healthy and productive population is one of the main national interests of any country, building an effective health care system is a matter of national importance. Affordable health insurance and widespread expansion of public health programs, the provision of free access to vaccinations, and the creation of a compulsory insurance system based on the European type of insurance can be part of this solution. However, we also need to consider economic, social, and cultural factors that can be potential obstacles to improving the medical system.

4. As an example, which systems should be aligned, we consider the described systems of Japan and South Korea. Despite their differing approaches to budgeting and government influence, they have managed to create fairly effective mixed health systems, where the right to health is protected for every citizen, and the costs of both an individual and societies are exemplary in comparison with other systems of states of their level of development.

5. This crisis can and should be a good opportunity to improve access to healthcare, help find a balance between the interests of business and society. It is worth starting to work on the problems we have described in medical insurance systems as soon as possible to avoid even more possible victims and not to waste time while this topic is on the agenda. 


\section{REFERENCES}

American College of Physicians-American Society of Internal Medicine. (1999). No health insurance? It's Enough to Make You Sick - Scientific Research Linking the Lack of Health Coverage to Poor Health. In

https://www.acponline.org/acp_policy/policies/no_health_insurance_scientific_ research_linking_lack_of_health_coverage_to_poor_health_1999.pdf.

American Hospital Association. (2020). New AHA Report: Losses Deepen For Hospitals \& Health Systems. In https://www.aha.org/press-releases/2020-06-30-new-ahareport-losses-deepen-hospitals-health-systems.

Ayanian, J. Z., Weissman, J. S., Schneider, E. C., Ginsburg, J. A. \& Zaslavsky, A. M. (2009). Unmet health needs of uninsured adults in the United States.

DOI: 10.1001/jama.284.16.2061.

Baicker, K., Taubman, S. L., Allen, H. L., Bernstein, M., Gruber, J. H., Newhouse, J. P., Schneider, E. C., Wright, B. J., Zaslavsky, A. M. \& Finkelstein. (2013). The Oregon Experiment-Effects of Medicaid on Clinical Outcomes. The New England Journal of Medicine, 368(18), 1713-1722. DOI: 10.1056/NEJMsa1212321.

Banthin, J., Simpson, M., Buettgens, M., Blumberg, L. J. \& Wang, R. (July 13, 2020). Changes in Health Insurance Coverage Due to the Covid-19 Recession. Urban Institute. In https://www.urban.org/research/publication/changes-healthinsurance-coverage-due-covid-19-recession.

Becton, J. L. J., Cheng, L. \& Nieman, L. Z. (2008). The effect of lack of insurance, poverty and pediatrician supply on immunization rates among children 19-35 months of age in the United States. The Journal of Evaluation in Clinical Practice, 14(2), 248-253. DOI: 10.1111/j.1365-2753.2007.00841.x.

Bodenheimer, T. \& Pham, H. H. (2010). Primary Care: Current Problems and Proposed Solutions. Health Affairs, 29(5), 799-805. DOI: 10.1377/hlthaff.2010.0026.

Brown, E. R., Ojeda, V. D., Wyn, R. \& Levan, R. (2000). Racial and ethnic disparities in access to health insurance and health care. UCLA Center for Health Policy Research and the Henry J. Kaiser Family Foundation. In http://healthpolicy.ucla.edu/publications/Documents/PDF/Racial\%20and\%20Et hnic\%20Disparities\%20in\%20Access $\% 20$ to $\% 20$ Health\%20Insurance\%20and $\% 20$ Health\%20Care.pdf.

Buchmueller, T. C., Grumbach, K., Kronick, R. \& Kahn, J. G. (2005). The Effect of Health Insurance on Medical Care Utilization and Implications for Insurance Expansion: A Review of the Literature. Medical Care Research and Review, 62(1), 3-30. DOI: 10.1177/1077558704271718.

Campbell, D. (July 8, 2019). NHS operations cancelled as consultants work to rule in pensions standoff. The Guardian. In https://www.theguardian.com/society/2019/jul/08/nhs-faces-existential-threatas-senior-doctors-work-to-rule. 
Realization of the Right to Health Protection in Insurance Medicine: the first experience...

CBS Los Angeles. (2020). Lancaster Teen Who Died Of Possible Covid-19 Complications Lacked Insurance, Delaying Treatment. In

https://losangeles.cbslocal.com/2020/03/27/coronavirus-lancaster-teeninsurance/.

Cho, Y., Chung, H., Joo, H., Park, H. J., Joh, H.-K. \& Kim, J. W. (2020). Comparison of patient perceptions of primary care quality across healthcare facilities in Korea, A cross-sectional study. PLoS ONE, 15(3), e0230034. https://doi.org/10.1371/journal.pone.0230034.

Cohen, R. A., Terlizzi, E. P., Martinez, M. M. \& Cha, A.E. (2020). Health Insurance Coverage: Early Release of Estimates from the National Health Interview Survey, January-June 2019. National Health Interview Survey Early Release Program. In https://www.cdc.gov/nchs/data/nhis/earlyrelease/insur202005508.pdf.

Collins, S. R., Bhupal, H. K. \& Doty, M. M. (2019). Health Insurance Coverage Eight Years after the ACA. Common wealth fund. In https://www.commonwealthfund.org/publications/issue-briefs/2019/feb/healthinsurance-coverage-eight-years-after-aca.

Collins, S. R., Gunja, M. Z., Aboulafia, G. N., Czyzewicz, E., Kline, C. H., Rapoport, R. \& Glancey, S. (June 23, 2020). An Early Look at the Potential Implications of the Covid-19 Pandemic for Health Insurance Coverage. Rama on healthcare. In https://ramaonhealthcare.com/an-early-look-at-the-potential-implications-ofthe-covid-19-pandemic-for-health-insurance-coverage/.

Dorn, S. (July 13, 2020). The Covid-19 pandemic and resulting economic crash have caused the greatest health insurance losses in American history. Families USA. In https://familiesusa.org/resources/the-covid-19-pandemic-and-resultingeconomic-crash-have-caused-the-greatest-health-insurance-losses-in-americanhistory/.

Douthit, N., Kiv, S., Dwolatzky, T. \& Biswas, S. (2015). Exposing some important barriers to health care access in the rural USA. Public Health, 129(6), 611-20. DOI: $10.1016 /$ j.puhe.2015.04.001.

FAIR Health, Inc. (2020). The Projected Economic Impact of the Covid-19 Pandemic on the US Healthcare System. In https://s3.amazonaws.com/media2.fairhealth.org/brief/asset/Covid-19\%20$\% 20$ The $\% 20$ Projected $\% 20$ Economic $\% 20$ Impact $\% 20$ of $\% 20$ the $\% 20$ Covid19\%20Pandemic\%20on\%20the\%20US\%20Healthcare\%20System.pdf.

Freeman, J. D., Kadiyala, S., Bell, J. B. \& Martin, D. P. (2008). The Causal Effect of Health Insurance on Utilization and Outcomes in Adults: A Systematic Review of US Studies. Medical Care, 46(10), 1023-1032.

DOI: 10.1097/MLR.0b013e318185c913.

Fullman, N., Yearwood, J., Abay, S.A. \& Abbafati C. (2018). Measuring performance on the Healthcare Access and Quality Index for 195 countries and territories and selected subnational locations: a systematic analysis from the Global Burden of Disease Study 2016. GBD 2016 Healthcare Access and Quality Collaborators. DOI: 10.1016/S0140-6736(18)30994-2. 
Giordano, C. (August 8, 2019). Treat NHS patients in private hospitals to cut waiting lists, government urged. Independent. In https://www.independent.co.uk/news/health/nhs-operation-waiting-list-privatehospitals-a9047661.html.

Goncharona, O. (June 24, 2019). The Right Korea: How Direct Government Financing Of Health Care Combines With Hard Competition in the Medical Services Market. Vademecum. In https://vademec.ru/article/nuzhnaya_koreya_vademecum_podglyadel_u_dalnevostochnogo_soseda_kak_pryamoe_gosfinansirovanie_zdrav/?fbclid=IwAR0zbOIqK3Lq9dp63TIX _Ibu-toaVUFppCWSqwWwC8ZpyipUk8qVb2ZtK94.

Harris, S., Sondel, J. \& Schneider, G. S. (April 10, 2020). Cash-starved hospitals and doctor groups cut staff amid pandemic. The Washington Post. In https://www.washingtonpost.com/health/starved-for-cash-hospitals-and-doctorgroups-cut-staff-amid-pandemic/2020/04/09/d3593f54-79a7-11ea-a130df573469f094_story.html.

Institute of Medicine (US). (2009). America's Uninsured Crisis: Consequences for Health and Health Care. Washington (DC): National Academies Press. DOI: $10.17226 / 12511$.

Kaiser Family Foundation. (2019). Health Insurance Coverage of the Total Population. In https://www.kff.org/other/state-indicator/totalpopulation/?dataView $=1 \&$ currentTimeframe $=0 \&$ selectedDistributions=employ er\&sortModel=\%7B\%22colId\%22:\%22Location \%22,\%22sort\%22:\%22asc\%22 $\% 7 \mathrm{D}$.

Kliff, S. (June 16, 2020). Most Coronavirus Tests Cost About \$100. Why Did One Cost $\$ 2,315$ ? The New York Times. In https://www.nytimes.com/2020/06/16/upshot/coronavirus-test-cost-varieswidely.html.

Kurani, N., Pollitz, K., Cotliar, D., Shanosky, N. \& Cox, C. (July 15, 2020). Covid-19 Test Prices and Payment Policy. Health System Tracker. In https://www.healthsystemtracker.org/brief/covid-19-test-prices-and-paymentpolicy/.

Lee, S. Y., Kim, C. W., Seo, N. K. \& Lee, S. E. (2017). Analyzing the Historical Development and Transition of the Korean Health Care System. Osong public health and research perspectives, 8(4), 247-254. https://doi.org/10.24171/j.phrp.2017.8.4.03.

Majerol, M., Newkirk, V. \& Garfield, R. (2015). The Uninsured: A Primer: key facts about health insurance and the uninsured in the era of health reform. Kaiser Family Foundation. In http://files.kff.org/attachment/primer-the-uninsured-aprimer-key-facts-about-health-insurance-and-the-uninsured-in-the-era-ofhealth-reform.

Matsuda, S. (2019). Health Policy in Japan-Current Situation and Future Challenges. JMA Journal, 2(1), 1-10. DOI: 10.31662/jmaj.2018-0016. 
Realization of the Right to Health Protection in Insurance Medicine: the first experience...

McWilliams, J. M., Zaslavsky, A. M. \& Meara, E. (2013). Impact of Medicare Coverage on Basic Clinical Services for Previously Uninsured Adults. JAMA, 290(6), 757-764. DOI:10.1001/jama.290.6.757.

Mehrotra, A., Chernew, M., Linetsky, D., Hatch, H. \& Cutler, D. (2020). The Impact of the Covid-19 Pandemic on Outpatient Visits: A Rebound Emerges. In https://www.commonwealthfund.org/publications/2020/apr/impact-covid-19outpatient-visits.

National Association of Community Health Centers and the Robert Graham Center. (2007). Access denied: a look at America's medically disenfranchised. In https://www.graham-center.org/content/dam/rgc/documents/publicationsreports/monographs-books/Access\%20Denied.pdf.

U.S. Department of Labor (2020). News release: the employment situation-September 2020. Washington, DC: Bureau of Labor Statistics. In In https://www.bls.gov/news.release/pdf/empsit.pdf.

Nomura, H. \& Nakayama, T. (2005). The Japanese healthcare system. BMJ (Clinical research ed.), 331(7518), 648-649. DOI:10.1136/bmj.331.7518.648.

Pimpertz, J. (May 30, 2017). Kein Spielraum für Wahlgeschenke: Wie die Demografie die privaten Haushalte belastet. In https://www.insm-oekonomenblog.de/16590kein-spielraum-fuer-wahlgeschenke-wie-die-demografie-die-privatenhaushalte-belastet/.

Saad, L. (December 9, 2019). More Americans Delaying Medical Treatment Due to Cost. Gallup. In https://news.gallup.com/poll/269138/americans-delaying-medicaltreatment-due-cost.aspx.

Sawyer, B. \& Cox, C. (December 7, 2018). How does health spending in the U.S. compare to other countries? Health System Tracker. In https://www.healthsystemtracker.org/chart-collection/health-spending-u-scompare-countries.

Skinner, A. C. \& Mayer, M. L. (2007). Effects of insurance status on children's access to specialty care: a systematic review of the literature. BMC Health Services Research, 7, Article number: 194. DOI: 10.1186/1472-6963-7-194.

Starfield, B., Shi, L. \& Macinko, J. (2005). Contribution of Primary Care to Health Systems and Health. The Milbank Quarterly, 83(3), 457-502.

DOI: 10.1111/j.1468-0009.2005.00409.x.

Sung, S. \& Park, H.A. (2019). Perceived cultural differences in healthcare for foreign patients visiting South Korea: tool development and measurement. BMC Health Serv Res 19, 197. DOI: 10.1186/s12913-019-3965-9.

Tolbert, J., Orgera, K. \& Damico, A. (November 6, 2019). Key Facts about the Uninsured Population. KFF. In https://www.kff.org/uninsured/issue-brief/key-facts-aboutthe-uninsured-population/.

U.S. Department of Health and Human Services Office of Inspector General. (2020).

Hospital Experiences Responding to the Covid-19 Pandemic: Results of a National Pulse Survey March 23-27, 2020. In https://oig.hhs.gov/oei/reports/oei-06-20-00300.asp. 
United Nations. (1966). International Covenant on Economic, Social and Cultural Rights. In https://www.ohchr.org/en/professionalinterest/pages/cescr.aspx.

Watkins, J., Wulaningsih, W., Zhou, C.D., Marshall, D.C., Sylianteng, G.D.C., Rosa, P.G.D., Miguel, V.A., Raine, R., King, L.P. \& Maruthappu, M. (2017). Effects of health and social care spending constraints on mortality in England: a time trend analysis. BMJ Open, 7(11). In https://bmjopen.bmj.com/content/7/11/e017722.

Worldometers. (2020). Coronavirus Cases. In https://www.worldometers.info/coronavirus/.

Zuvekas, S.H. \& Taliaferro, G.S. (2003). Pathways to Access: Health Insurance, the Health Care Delivery System, and Racial/Ethnic Disparities, 1996-1999. Health Affairs, 22(2), 139-153. DOI: 10.1377/hlthaff.22.2.139. 